\title{
De conventionele RCT voor trauma- en orthopedisch chirurgen: geen heilige graal
}

R. M. Houwert, M.H.J. Verhofstad, F. Hietbrink, M.C. Kruyt

R.M. Houwert, chirurg, Utrecht Trauma Centrum \& fellow Traumachirurgie Antonius Ziekenhuis, Nieuwegein

M.H.J. Verhofstad, traumachirurg, afdeling Traumachirurgie, Erasmus MC, Rotterdam F. Hietbrink, traumachirurg, afdeling Traumachirurgie, Universitair Medisch Centrum Utrecht, Utrecht

M.C. Kruyt, orthopedisch chirurg, afdeling Orthopedie, Universitair Medisch Centrum Utrecht, Utrecht

\section{Samenvatting}

Conventionele RCT's voor trauma- en orthopaedisch chirurgisch onderzoek zijn moeilijk uitvoerbaar door chirurg- en patiënt gerelateerde redenen. Grote regionale cohortstudies en (quasi-) experimentele designs met vooraf gedefinieerde uitkomst parameters en een fulltime onderzoeker bieden een oplossing. De conventionele RCT kan dan worden ingezet voor specifiek gedefinieerde problemen die voortkomen uit de resultaten van deze studies.

\section{Abstract}

The conventional Randomised Controlled Trial for trauma- and orthopaedic surgeons: not the Holy Grail

This article describes the limitations of conventional Randomised Controlled Trials for orthopaedic- and trauma surgeons. Major challenges are recruitment of patients, participation of surgeons, the learning curve of surgical procedures, sufficient follow-up 
rates and treatment standardization. Prospective observational studies and (quasi-) experimental designs may provide a solution. The conventional Randomised Controlled Trial can be used for specifically defined research questions evolving out of prospective observational and (quasi-) experimental studies.

\section{Inleiding}

De randomised controlled trial (RCT) wordt gezien als de gouden standaard voor klinisch experimenteel onderzoek terwijl aan observationeel onderzoek relatief weinig waarde wordt toegedicht. ${ }^{1}$ Een recente meta-analyse laat echter zien dat de verschillen in uitkomst tussen RCT's en observationeel onderzoek van een chirurgische techniek nauwelijks van elkaar verschillen. ${ }^{2}$

In een conventionele RCT wordt een behandeling uitgevoerd in een interventiegroep en een controlegroep. De toewijzing voor de betreffende groep wordt door het lot bepaald (randomisatie). Hierdoor zijn behandelgroepen in principe vergelijkbaar. Bij voorkeur wordt een conventionele RCT geblindeerd uitgevoerd, zodat noch de patiënt (en behandelend arts), noch de onderzoeker bevooroordeeld zou kunnen zijn over de uitkomst. De waarde van de RCT binnen de orthopedische traumachirurgie staat al langer ter discussie. Er wordt veel onderzoek in trialverband gedaan, maar dit heeft nog niet geleid tot grote veranderingen in beleid. ${ }^{3}$ Ook zijn er grote verschillen tussen de snijdende en beschouwende specialismen betreffende het gebruik van de RCT in de kliniek. Zo bleek de behandeling van chirurgische patiënten slechts half zo vaak gebaseerd op RCT-resultaten als die van internistische patiënten. ${ }^{4}$ Dit verschil heeft een oorzaak: voor chirurgisch onderzoek schieten zowel de chirurg als de conventionele RCT op een aantal punten tekort.

In dit artikel willen wij de problemen van de conventionele RCT voor trauma- en orthopedisch chirurgen bespreken, waar mogelijk een oplossing aandragen per probleem en aanbevelingen doen voor de toekomst.

\section{Probleemanalyse: inclusie door randomisatie}

Een hoog inclusiepercentage ( $>50 \%$ ) is essentieel voor betrouwbaar klinisch onderzoek. Zo'n onderzoek is immers een steekproef die alleen zinvol is wanneer die 
representatief is voor de hele populatie. Een laag inclusiepercentage heeft de suggestie van selectiebias. Een probleem van de conventionele RCT is het mislopen van inclusies door voorkeur van patiënten. Een recent voorbeeld hiervan is de BRAIST-studie naar het nut van bracetherapie bij scoliose. ${ }^{5}$ In deze studie was het inclusiepercentage voor randomisatie dermate laag $(<15 \%)$ dat de onderzoekers gebruik hebben gemaakt van een extra cohort dat bestond uit een observationele prospectieve studiegroep (vrije keuzebehandeling).

Ook chirurgen hebben vaak een vooroordeel over een operatie en daardoor moeite met randomisatie. ${ }^{4}$ Hierdoor doen zij óf niet mee aan multicenteronderzoek óf worden de patiënten selectief geïncludeerd. Als voorbeeld werd in onze claviculastudie bij $21 \%$ (44/209) van de potentiële patiënten de studie niet eens besproken, omdat de chirurg een voorkeur had voor een van beide behandelingen. ${ }^{6}$

\section{Mogelijke oplossing}

Bij prospectieve cohortstudies met instrumentele-variabelenanalyse wordt een pseudorandomisatie gedaan op basis van een instrumentele variabele. Dit is een factor die de behandeling wel beïnvloedt, maar theoretisch niet gerelateerd is aan het effect van de behandeling. ${ }^{7}$ Een voorbeeld van een instrumentele variabele is het centrum waar de patiënt wordt behandeld, wanneer is gekozen voor één behandeloptie per deelnemend centrum. De pseudo-randomisatie vindt dan plaats op basis van het centrum waar de patiënt behandeld wordt. Zo wordt de routine niet doorbroken en is het inclusiepercentage maximaal. Het voordeel van dit design is dat de allocatie niet willekeurig is, maar wordt aangepast aan de expertise van de chirurg. Een nadeel van dit design blijft dat er per centrum systematische verschillen in bijvoorbeeld postoperatieve zorg kunnen zijn, waardoor er een risico blijft op performance bias.

\section{Probleemanalyse: blindering}

Een ander probleem is dat (dubbele) blindering niet altijd mogelijk is, hetzij om praktische (voorbeeld wondgrootte) hetzij om ethische redenen (invasieve shambehandeling). Blindering wordt toegepast om observer bias te voorkomen. Observer bias treedt op als de resultaten afwijken van de werkelijkheid door 
vooringenomenheid van de beoordelaars of de patiënt over een bepaalde uitkomst. Het belang van blindering van de patiënt werd recentelijk weer duidelijk in een RCT met een shamgroep, waarin het eerder waargenomen effect van de vertebroplastiek niet meer aantoonbaar bleek. ${ }^{8}$

Observer bias kan ook optreden bij sterk subjectieve (lees beoordelaarafhankelijke) uitkomstmaten en speelt minder bij harde eindpunten zoals mortaliteit.

\section{Mogelijke oplossing}

De oplossing is een (idealiter geblindeerde) onderzoeker die de patiënten beoordeelt, onafhankelijk van de hoofdbehandelaar (operateur). Hiermee wordt de observer bias verminderd. Bijkomend voordeel van een toegewijde onderzoeker is dat de loss to follow-up aanzienlijk wordt verminderd. De onderzoeker kan aanwezig zijn bij alle follow-upmomenten en bouwt een band op met de patiënt, wat commitment van de patiënt aan het onderzoek ten goede kan komen. In onze claviculastudie resulteerde dit in een loss to follow-up van slechts $3 \%$ na één jaar. ${ }^{6}$

\section{Probleemanalyse: confounding}

Er is sprake van confounding wanneer het causale verband tussen de determinant en de uitkomst wordt verstoord in een bepaalde richting (= bias) door een derde factor, de confounder. Waar de menselijke handeling in een beschouwende RCT meestal bestaat uit een laagcomplexe handeling (bijvoorbeeld het aanhangen van intraveneuze medicatie), is de essentie van een chirurgische behandeling dat de handeling complex is. Een voorbeeld in chirurgisch onderzoek is de expertise van het chirurgisch team met een van de behandelingen van de studie: de performance bias. Deze vorm van bias wordt onder andere weergegeven in de leercurve. Meer ervaring met een bepaalde interventie resulteert in betere resultaten, waardoor geen eerlijke vergelijking meer mogelijk is. Voor complexe operaties kan een dergelijke leercurve langdurig zijn. Dit fenomeen is goed beschreven in de wervelkolomchirurgie. ${ }^{9}$

\section{Mogelijke oplossing}

Deze performance bias wordt voorkomen met prospectieve cohortstudies wanneer chirurgen de behandeling uitvoeren waar ze zich het meest comfortabel bij voelen. Voor 
het aandragen van dergelijke prospectieve series kunnen dan ook volumenormen worden afgesproken, zodat de leercurve gegarandeerd doorlopen is.

Een andere oplossing is de surgical equipoise methode. ${ }^{9}$ Hierbij worden aandoeningen of behandelingen waarover geen consensus bestaat tussen twee 'scholen' (= equipoise) met elkaar vergeleken. Een voorbeeld is de behandeling van thoracolumbale wervelfracturen, operatief of niet-operatief. Alle patiënten zijn prospectief vervolgd, maar retrospectief geïncludeerd in het onderzoek door een geblindeerd panel op basis van equipoise (agree to disagree). De patiënt is dan al optimaal behandeld volgens het protocol van de betreffende school. Wanneer beide groepen (zoals te verwachten) vergelijkbaar zijn, kunnen de vooraf geformuleerde uitkomstmaten worden vergeleken.

\section{Probleemanalyse: relevantie voor klinische praktijk}

Naast de eerder genoemde lage inclusiepercentages en verstoring van de dagelijkse praktijk, geeft een RCT slechts antwoord op één vraag in termen van één effect binnen één bepaalde periode. Tevens zijn in- en exclusiecriteria van RCT's soms zo strikt dat er eigenlijk sprake is van een selecte steekproef. Hierdoor is een RCT niet meer representatief voor de dagelijkse klinische praktijk.

\section{Mogelijke oplossing}

De oplossing zit in grote aantallen en langetermijnfollow-up. Grote aantallen geven goed inzicht in de dagelijkse klinische praktijk en kunnen bovendien zeldzame complicaties aan het licht brengen en inzicht geven in het klinisch beloop van dergelijke complicaties. Een voorbeeld is aseptische loslating van een heupprothese na 10-15 jaar, een fenomeen dat inzichtelijk is gemaakt door de Zweedse heupregistratiedatabase. ${ }^{10}$

\section{Andere (quasi-)experimentele designs}

Het grootste nadeel van observationeel onderzoek is dat er niet gecorrigeerd kan worden voor bekende en onbekende prognostische factoren. Een alternatief voor het beantwoorden van een therapeutische onderzoeksvraag binnen de snijdende vakken is een expertisebased RCT. ${ }^{11}$ Met een dergelijk design worden patiënten niet meer gerandomiseerd voor een bepaalde behandeling, maar voor een behandelaar met expertise. Ondanks dat de behandeling nog steeds door het lot wordt bepaald, zal de 
angst voor randomisatie afnemen bij de mogelijke studieparticipant, omdat de operatie door een 'expert' wordt verricht. Tevens wordt het risico op confounding verkleind omdat de operateurs de leercurve reeds hebben doorlopen.

Nog andere oplossingen zijn cluster-RCT's of studies met een quasi-experimenteel design, waarbij in een multicenterstudie per centrum één behandeloptie wordt toegepast (de eerder besproken instrumentele-variabeleanalyse) en de verdeling aan het lot wordt overgelaten.

Zoals eerder aangeven, hebben ook chirurgen vaak een vooroordeel over een bepaalde behandeling en derhalve moeite met randomisatie. Door rekening te houden met de expertise en voorkeur van de chirurg, zal in onderzoeken met een expertisebased design de procedure niet meer worden verricht door een minder ervaren of minder gemotiveerde operateur. Deveraux laat in zijn studie uit 2008 inderdaad zien dat orthopedisch chirurgen een voorkeur hebben voor een expertisebased design in vergelijking met de conventionele RCT. ${ }^{12}$

\section{Toekomst}

Voor effectief onderzoek naar chirurgische behandelingen zou de basis meer moeten liggen in grote regionale of landelijke prospectieve cohortstudies en (quasiJexperimentele designs. Hierin kunnen chirurgen de behandeling uitvoeren waarin ze het meest bekwaam zijn in een omgeving die op deze behandeling is ingesteld. Dit ondervangt de problemen die ontstaan met inclusie, blindering en confounding door chirurgische vaardigheden. Voorwaarde voor deze studies is dat er consensus moet zijn betreffende de nabehandeling, de registratie van complicaties, de follow-upduur en de wijze van follow-up (bijvoorbeeld wel of geen röntgenonderzoek). Idealiter is er in ieder groot centrum een permanente kracht aanwezig die zorg draagt voor een zo gestandaardiseerd mogelijke follow-up en registratie van alle geïncludeerde patiënten. Vanuit de chirurgen moet er commitment zijn aan de deelname. Deelname verhoogt de transparantie en daarmee de kwaliteit van zorg. Een goed voorbeeld van een dergelijke onderzoeksopzet is de Hummer-studie: een prospectief cohortonderzoek naar de beste behandelmethode voor fracturen van de humerusschacht. ${ }^{13}$ Ter aanvulling kan er eventueel op basis van deze studies per specifiek gedefinieerd probleem een conventionele RCT worden opgezet. 


\section{Verantwoording}

Wij danken dr. M.G.W. Dijkgraaf voor het kritisch beoordelen van het manuscript.

Wij danken drs. L.L. van Spengler, dr. E.J.M.M. Verleisdonk, professor dr. L.P.H. Leenen en professor F.C. Oner, voor het kritisch beoordelen van het manuscript en het steunen van de filosofie.

\section{Literatuur}

1. Black N. Why we need observational studies to evaluate the effectiveness of health care. BMJ. 1996;312:1215-8.

2. Abraham NS, Byrne CJ, Young JM, Solomon MJ. Meta-analysis of well-designed nonrandomized comparative studies of surgical procedures is as good as randomized controlled trials. J Clin Epidemiol. 2010;63:238-45.

3. Court-Brown CM, Mc Queen MM. How useful are meta-analyses in orthopaedic trauma? J Trauma. 2011;5:1395-9.

4. McCulloch P, Taylor I, Sasako M, Lovett B, Griffin D. Randomised trials in surgery: problems and possible solutions. BMJ. 2002;324:1448-51.

5. SL Weinstein, LA Dolan, JG Wright, MB Dobbs. Effect of bracing in adolescents with idiopathic scoliosis. N Engl J Med. 2013;369:1512-21.

6. Meijden OA van der, Houwert RM, Hulsmans M, et al. Operative treatment of dislocated midshaft clavicular fractures: Plate or intramedullary nail fixation? A randomized controlled trial. J Bone Joint Surg Am. 2015;97(8):613 -9.

7. Boef AG, Cessie S le, Dekkers OM. Instrumentele-variabele-analyse. Ned Tijdschr Geneeskd. 2013;157:A5481.

8. Kallmes DF, Comstock BA, Heagerty PJ, et al. A randomized trial of vertebroplasty for osteoporotic spinal fractures. N Engl J Med. 2009;361:569-79. 
9. Stadhouder A, Oner FC, Wilson KW, et al. Surgeon equipoise as an inclusion criterion for the evaluation of nonoperative versus operative treatment of thoracolumbar spinal injuries. Spine J. 2008;8:975-81.

10. Herberts $P$, Malchau H. Long-term registration has improved the quality of hip replacement: a review of the Swedish THR Register comparing 160,000 cases. Acta Orthop Scand. 2000;71:111-21.

11. Scholtes VA, Nijman TH, Beers L van, Devereaux PJ, et al. Emerging designs in orthopaedics: expertise-based randomized controlled trials. J Bone Joint Surg Am. 2012;94 Suppl 1:24-8.

12. Bednarska E, Bryant D, Devereaux PJ. Orthopaedic surgeons prefer to participate in expertise-based randomized trials. Clin Orthop Relat Res. 2008;466(7):1734-44.

13. Mahabier KC, Lieshout EM van, Bolhuis HW, et al. HUMeral shaft fractures: measuring recovery after operative versus non-operative treatment (HUMMER): a multicenter comparative observational study. BMC Musculoskelet Disord. 2014;15:39. 